\title{
Research and Review on the Public Policy Process of Internet Financial Supervision-Taking P2P Online Lending Platform as an Example
}

\author{
Zihao Ye \\ Department of Finance, Tianjin University of Finance and Economy, Tianjin 300222, China \\ 1009813854@qq.com
}

\begin{abstract}
As a new type of financial business mode combining Internet technology and financial industry, Internet finance has the characteristics of low cost, high efficiency, wide range and high risk. On the one hand, Internet finance plays an indispensable role in promoting the vigorous development of the financial industry and supplementing the original gaps in the industry. On the other hand, its involvement of Internet technology has caused certain difficulties for regulatory behavior. Therefore, from the perspective of analyzing the implementation of public policy and the process of the policy target group's responding to the policy, this paper takes the P2P online lending platform - a field of Internet finance where problems often take place as an example, and uses the "Smith's public policy model" to evaluate the effect of the regulatory policies currently implemented and make relevant comments.
\end{abstract}

Keywords: Internet finance, P2P online lending platform, Smith's public policy model.

\section{Introduction}

In recent years, with the development of Internet technology and the gradual opening of financial markets, China's Internet finance has ushered in a boom. In 2013, the development of China's Internet finance exceeded expectation both in scale and speed, which made Internet finance become the focus of attention from all walks of life. According to data from iResearch, the scale of third-party payment transactions in China hit 9 trillion yuan in 2015; the number of new platforms for P2P online lending reached the peak in recent years from the second half of 2014 to 2015 and the highest number of newly added was more than 250. All this has shown that China's Internet finance is rapidly moving forward.

So far, China has not yet had an independent department for Internet financial supervision. The department responsible for regulating Internet finance is the National Internet Finance Association of China established by China Banking Regulatory Commission, which is directly supervised and managed by the central bank. As for legislation, emphasis is put on legislative supervision in specific areas such as $\mathrm{P} 2 \mathrm{P}$, crowdfunding, and third-party payment. However, systematic legislation on Internet finance remains to be discussed by the academic community. In addition, the supervision of Internet finance is confronted by the following problems: the ownership of the regulatory system is difficult to define; regulatory policies and legislation are lagging; and current regulatory technology cannot meet regulatory requirements.

This paper begins with analysis of existing policies, considers the policy transmission path and possible outcomes, analyzes relevant policies of Internet finance, and finally puts forward relevant suggestions.

\section{Literature Review}

\subsection{Definition of Internet Finance}

Xie Ping first proposed the concept of Internet finance which covered transactions and organizations of various financial business modes ranging from traditional intermediary financial markets to financial markets without financial intermediaries [1]. Wu Xiaoqiu pointed out that Internet finance was based on information technology and associated with a variety of financial business modes besides investment areas [2]. According to official literature, China Financial 
Stability Report 2014 could be regarded as the official definition of Internet finance. In this document, Internet finance was defined as "the use of the Internet and mobile information technology to realize financial integration and the emerging business model involving functions such as payment and information intermediary.

As for research on Internet finance, the focus is mainly on defining and differentiating the nature of Internet finance. Supporters believe that the impact of the Internet on the financial industry is transformative. Pi Tianlei pointed out that Internet finance "was different from both indirect financing represented by commercial banks and direct financing based on capital market" [3], and was divided into Internet channel finance, Internet micro-finance and pure Internet finance based on different degrees of influence of Internet technology on finance. Xie Ping and Zou Chuanwei pointed out that the impact of modern information technology on the financial industry would be disruptive [4]. Another focus is on the regulation and risk management of Internet finance. Based on the perspective of information tools, Yang Dong studied the relationship between information and supervision in the process of supervision from the phenomenon of information asymmetry [5]. In addition to detailed discussion of the Internet financial regulatory mechanism, the academic community has also discussed the relationship between regulation and innovation in Internet financial operations.

\subsection{China's Internet Financial Market}

Subject to many factors, the development of China's traditional financial industry is relatively backward compared with the world level. For a long time, China's financial industry was monopolized by the four major state-owned banks. However, due to the cost factors, the development of niche markets in the traditional financial industry has been very limited.

Internet finance has the characteristics of low cost and high efficiency, which reduces the cost of focusing on the tail customers of Internet financial service providers, enabling single small-scale markets to gather and become a market of a certain scale. At the same time, the popularity of the Internet has also reduced the cost of seeking customized financial services, thus increasing the market demand for Internet finance. The mainstream models of Internet finance are third-party payment, P2P online lending, crowdfunding, e-commerce microfinance and so on.

Taking the data collected from iResearch as an example:

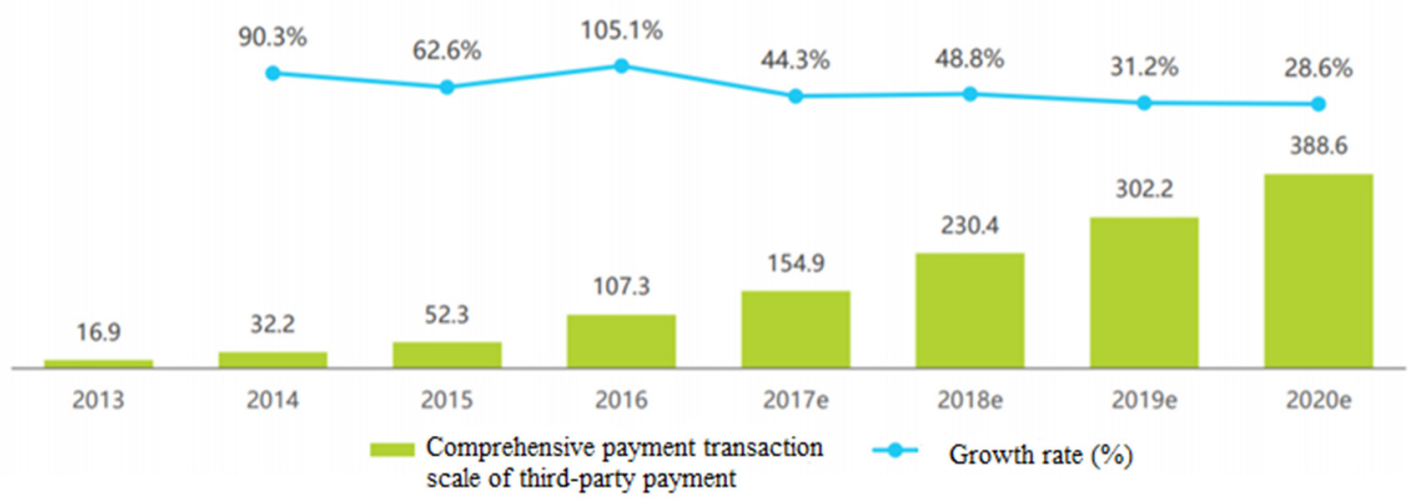

Source: The People's Bank of China, comprehensive business interview, market disclosure, calculation made based on iResearch statistical model

Fig. 1 China's comprehensive payment transaction scale third-party payment from 2013 to 2020

It can be seen from the figure; the scale of third-party payment comprehensive payment transactions went through explosive growth in 2016. Although the growth of subsequent forecast data slowed down, the fact that the overall growth rate of third-party payment remained high was unquestionable. At the same time, third-party payment also promoted the increase in non-cash 
payments, making the entire payment process more convenient, efficient, and fast, and solving the credit problem that often caused by traditional payments.
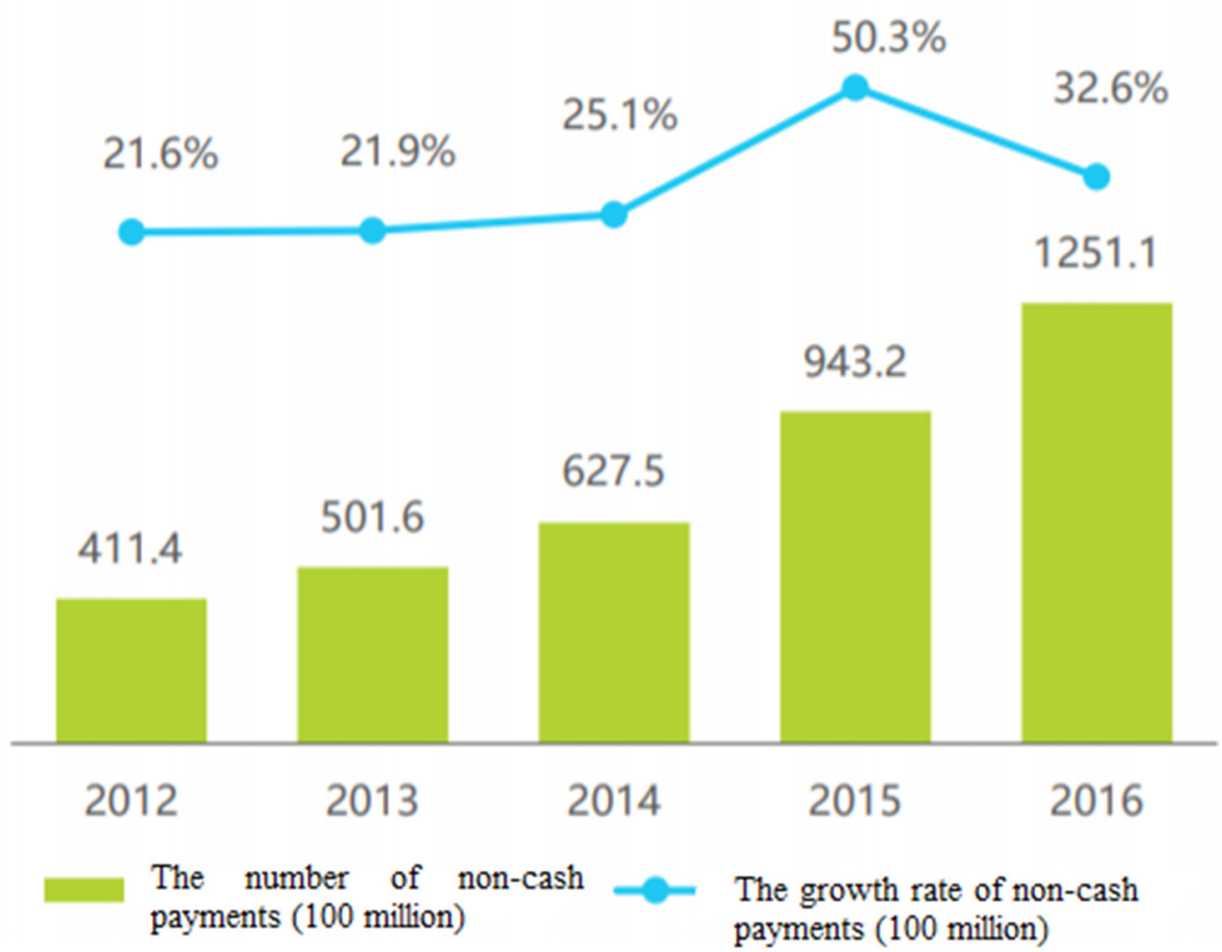

Fig. 2 the number of non-cash payments and growth rate in China from 2012 to 2016

\subsection{China's Internet Financial Policies}

From the aspect of supervision, China's Internet finance regulatory policies have gradually shifted from the original subjective supervision to behavioral supervision. Considering the innovative development of the financial industry under the application of Internet technology, the behavior and scope of each Internet financial entity also undergo constant change. Therefore, categories of Internet finance industry are obviously crossed, and it is difficult to carry out tracked supervision on all financial behaviors of specific subjects [6].

The starting point of China's Internet finance policy is to seek a balance between supervision and innovation, and at the same time improve various laws pertaining to Internet finance and reduce the legal risks caused by the lag in legislation. While pursuing the effect of regulation, these policies also pay attention to protecting the rights and interests of consumers.

\subsection{Policy Models}

\subsubsection{Institutional Model}

The institutional model believes that policy is the output of the institution. The implementation of public policies should be closely linked to policies themselves, and policies can become public policies only after they are adopted, promoted, and carried out by agencies within the institution [7][8]. Relevant government institutions endowing policies with legitimacy means three points: first, a decision always tends to complete its legalization process after it emerges from a good institution; second, after a decision is legalized, it must be regarded as a legal obligation, thus requiring citizens to obey; universality means that the government's decision-making will affect everyone under its rule and compulsory means that the state monopolizes social coercive power; at the same time, the new 
institutionalists believe that the effect of a policy is very close to its institution, so to ensure that the policy is effective, the first thing is to ensure sound operation of the decision-making institution [9].

\subsubsection{Process Model}

The "process model", also known as the "policy life cycle model", advocates procedural and stepwise research on political and public policies including problem emergence, problem identification, decision-making agenda, policy planning, policy implementation, evaluation of policy implementation, policy adjustment, and policy termination [10]. The core of the entire policy process model is to regard public policies as a kind of political behavior. At the same time, this model considers the process of creating, implementing, and correcting the policy as a process featuring continuous dynamic change [11] [12].

\subsubsection{Progressive Model}

The "progressive model" or "progressive decision-making model" first requires decision-makers to gradually correct and supplement their own decisions based on past experience when making decisions. Secondly, each decision must be based on reality and then solve the shortcomings of the current policy system and achieve fundamental changes through the accumulation of changes. Finally, the progressive model emphasizes the stability of the decision-making process.

The progressive model is obviously conservative, and thus it is unable to cope with the decisionmaking under the condition of drastic changes and will even hinder the fundamental change of the institution under certain circumstances. In addition, the progressive model also has a lag in decisionmaking and cannot solve problems quickly. [13] [14].

\subsection{Policy Evaluation}

This paper uses the "policy implementation process model" to analyze the effectiveness of government financial supervision. The "policy implementation process model" was first proposed by American scholar TB Smith in his article The Process of Policy Implementation, which was used to analyze the effectiveness and factors of policy implementation and mainly focused on the following four factors that influenced the effectiveness of the policy: policy itself, policy enforcement agencies, target groups, and other environmental factors. At the same time, this model points out that policy implementation will create a "tension" in society, that is, the implementation will bring different effects to different social subjects, thus generating different feedback. This feature will lead to a deviation of policy effectiveness from expectation to some extent [15].

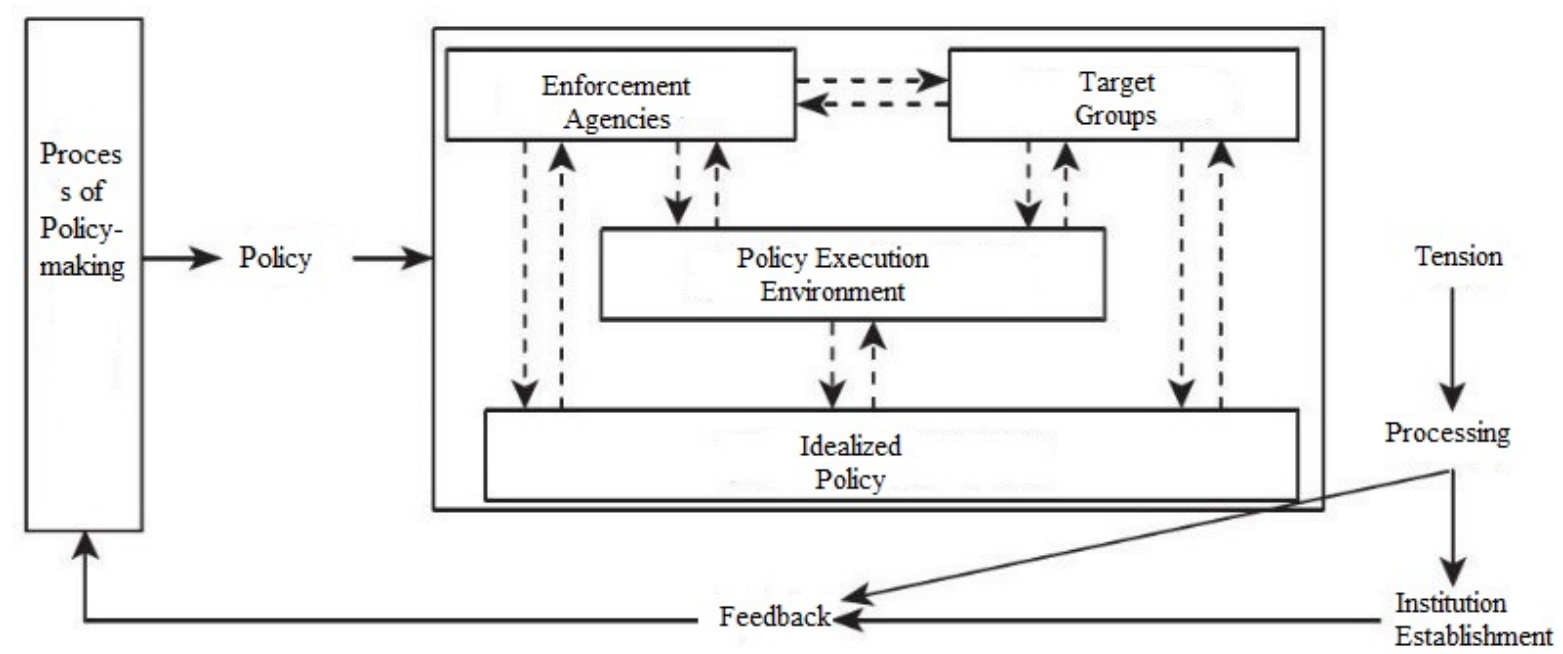

\subsubsection{Policy Itself}

Policy itself refers to its category and form and different cognition of the social groups for the policy under ideal conditions. The policy under certain ideal conditions needs to be effectively implemented so as to minimize or avoid deviation. Therefore, the formulation of the policy itself 
needs to meet the following characteristics: strong operability, specificity and completeness, and continuity and stability.

\subsubsection{Policy Enforcement Agencies}

The factor of policy enforcement agencies mainly includes the power structure, leadership model, and executive power of a certain policy enforcement agency. Macroscopically, policy implementation is mainly affected by the organizations that implement the policy. Therefore, relevant enforcement organizations need to set up reasonable institutions according to realities and improve the internal rules and regulations of these organizations. From a micro perspective, people who implement the policy also have an impact on the policy, which requires implementers to be equipped with a high level of execution and professionalism so as to implement the policy based on sound understanding of it.

\subsubsection{Target Group}

The target group refers to a specific group that must adjust their behavior after the policy is introduced. The factors of the target group affecting the policy mainly include the scale of the target group, its organizational structure, its cognition of the policy, and the pursuit of its own value.

\subsubsection{Other Environmental Factors}

Other environmental factors mainly include the natural environment and the social environment. Considering that the subject discussed in this article is the Internet financial market, the impact of the natural environment will not be discussed because it is negligibly small. Social environment includes political, economic, legal systems and other factors.

The main benefit of this assessment model lies in that policy makers tent to focus on the policy formulation itself in the past, while ignoring the target group of the policy and paying less attention to the policy enforcement agencies and other environmental factors on which the policy depends, which ultimately resulted in deviations that couldn't be underestimated. Therefore, it is particularly important to examine the implementation of a policy from other perspectives besides the policy itself.

\section{Empirical Analysis}

\subsection{Policy Analysis-Taking the Regulation of P2P Online Lending Platform as an Example}

\subsubsection{Analysis of the Current Situation}

(1) Development of Online Lending Platform

Since the emergence of online lending, it has always been at the critical point of risk, regulation and innovation. In 2007, the opening of Ppdai which is China's first online lending platform marked the start of China's online lending era. In 2011, Lufax (Shanghai, China) went online, becoming the first online lending platform with bank background. 2013 signified the first year of China's Internet finance; at the same time, online lending platforms went through explosive growth with the investment and financing events increasing from 12 in 2013 to 71 in 2014. In 2015, China officially incorporated the supervision of online lending into the responsibility of CBRC. In 2016, the promulgation of the Interim Measures for the Administration of the Business Activities of Online Lending Information Intermediary Institutions and the Guidelines for the Management and Registration of Online Lending Information Intermediaries improved China's regulatory system for Internet lending.

(2) Regulation of Online Lending Platforms

The main body responsible for supervision of China's online lending platforms includes the People's Bank of China, the CBRC, and the CSRC. Behind the adjustment of financial institutions is the fruit brought by China's emerging business modes represented by P2P. From the perspective of policies, China's supervision of the $\mathrm{P} 2 \mathrm{P}$ online lending platforms is mainly based on legal methods, accompanied with various guiding documents such as "Guidelines" and "Measures" [16].

At the same time, the supervision of online lending platforms is still confronted by some problems such as the lag in and lack of legislation. As a matter of fact, China has not yet formed a set of unified 
and sound laws for the supervision of the entire mode of Internet finance, and the legal provisions pertaining to Internet financial supervision are scattered in the Civil Law, Company Law, the Company Law, and the Contract Law. Therefore, the current "Interim Measures" has a lower legal status and may be less effective than the legal provisions compared with statute law [17] [18] [19]. In addition, the main body responsible for supervising lacks cooperation. Since P2P online lending belongs to Internet finance, it has distinctive features of Internet technology, that is, investors and lenders are widely distributed across the country, thus resulting in extremely rapid spread of negative events. This requires financial supervision institutions across the country to collaborate with each other so as to achieve information symmetry and coordination [20] [21]. Moreover, the supervision of online lending platforms still faces such problems as inadequate supervision experience, imperfect supervision methods, and incomplete credit information system [22] [23].

\subsubsection{Analysis of the Regulatory Policy Environment}

\section{(1) Top-level Policies}

China's supervision of the financial sector has experienced a developing process from being shallow, simple, brief and blank to being deep, complex, detailed and quality. Looking at China's policies introduced since 2000 , it is not difficult to see that the establishment of China's macro financial system has gradually become systematic and institutionalized.

In the "11 th Five-Year Plan", the Chinese government was more focused on improving the service of the financial system, and encouraged financial innovation from the perspective of the function, variety and quality of financial services. At that time, the awareness of supervising the macro financial system did not become the mainstream and the policies were still oriented to encourage financial markets. In the "12th Five-Year Plan", emphasis was mainly put on establishing the overall financial system which mainly included reforming financial institutions, building market systems, improving regulatory mechanisms, and strengthening financial supervision. It could be said that the framework of China's financial system in the "Twelfth Five-Year Plan" began to emerge, which mainly included requiring mutual coordination among financial regulatory agencies, attaching importance to risk management and control, and strengthening supervision over key financial institutions. In chapters referring to finance of the "13th Five-Year Plan", however, the government proposed a framework for diversifying financial institutions, improving the financial market system, and reforming financial regulatory institutions, among which items like "implementing full coverage of financial risk supervision" and "coordinating system management of key financial institutions" demonstrated China's efforts made in improving the regulatory system at this phase.

The supervision of $\mathrm{P} 2 \mathrm{P}$ online lending platforms is an indispensable part of financial supervision. Therefore, in recent years, the trend of $\mathrm{P} 2 \mathrm{P}$ policies has been basically consistent with that of the state's macro-regulation of finance.

(2) Supporting Policies

A. Legal Measures

As for the legal supervision of the online lending platform, various statutes mainly reflect two characteristics: First, it has a strong auxiliary nature. China's regulations on the supervision of P2P online lending platforms are still based on various interim rules and regulations. Second, the legislative level is weak. Currently, statutes only conduct supervision according to existing laws and regulations. (If a $\mathrm{P} 2 \mathrm{P}$ online lending platform violates the lending rules, it will be tried according to the relevant provisions of the Lending Law and the General Principles of the Civil Law. However, there is no legislative content specially pertaining to $\mathrm{P} 2 \mathrm{P}$ online lending platforms.) For instance, various regulations governing $\mathrm{P} 2 \mathrm{P}$ online lending platforms are mostly provisional regulations, and they are subject to various legal provisions.

Another important measure at the legal level is the highest judicial interpretation of P2P. In this respect, 2015 is a turning point. In 2015, the Provisions of The Supreme People's Court on Several Legal Issues Concerning the Application of Laws in the Trial of Private Lending Cases focused on dealing with the following key issues: first, defining the intermediary nature of $\mathrm{P} 2 \mathrm{P}$ lending platforms; second, affirming legal lending between enterprises; third, restricting interest rates of lending.

B. Administrative Measures 
In China, financial regulatory agencies represented by the "one bank and two commissions" under the State Council take responsibility for financial supervision through the introduction of various relevant policies, and various local agencies have offered cooperation according to the actual level of local development.

In current regulatory laws and policies, regulation of P2P online lending is still dominated by various interim rules. Macro-level policy documents were mainly promulgated in 2016, among which representatives were Interim Measures for the Administration of the Business Activities of Online Lending Information Intermediary Institutions, and Guidelines for the Management and Registration of Online Lending Information Intermediaries. These documents have led to the shift of P2P regulation from simple, sporadic guidelines to policy documents that gradually demonstrate the framework, laying the foundation for further improvement of the regulatory system and the introduction of regulatory policies by local regulators.

\section{Auditing Measures}

The legal basis for conducting auditing and supervision of P2P online lending platforms comes from the Guidelines for Information Disclosure of Business Activities of Internet Lending Information Intermediaries published in 2017. This policy document requires P2P platforms to disclose relevant audit financial reports. Meanwhile, National Internet Finance Association of China has specified three areas of audit report disclosure indicators: financial audit report, results of key audit areas, and important financing and liabilities information. On this basis, P2P online lending platforms are reviewed for compliance and authenticity.

At present, auditing is still less mandatory and audit measures of many platforms are ineffective and perfunctory. Therefore, research on the system design of audit measures needs to be improved.

\subsubsection{Execution Effect}

Although China's financial supervision system is increasingly sound and complete, the lending market has been regulated quite well after a series of regulatory policies are introduced, borrowing and lending have been on the track, P2P "thunderstorm" incidents are still common in recent years. According to relevant data, by the end of 2018, the number of P2P industry problem platforms will have hit 2,300. In the first half of 2018, nearly 800 companies had different levels of "difficulties in cash withdrawals" and "business termination and making off with money". It can be seen that there is still a long way to go before achieving more reasonable effect of P2P supervision.

From the perspective of Smith's "Policy Implementation Process Model", the reasons for the frequent occurrence of $\mathrm{P} 2 \mathrm{P}$ "thunderstorm" events can be analyzed from the following four points:

(1) Policy Analysis

Judging from the financial part of the "13th Five-Year Plan" released by the Chinese government, China's financial market is currently only in the initial stage of "emergence", and laws and regulations on P2P supervision overall are still not perfect. On the one hand, various "Guidelines" and "Interim Measures" are lacking effectiveness, and they are often in a passive situation when conflicting with relevant mature laws. On the other hand, there are no special laws pertaining to $\mathrm{P} 2 \mathrm{P}$ regulation at the legislative level. Moreover, the fact that specific laws and regulations governing P2P online lending platforms are scattered among many other laws undoubtedly increases the cost of judicial investigation.

The fifth national conference on financial work held in 2017 pointed out that it was necessary to "strengthen functional supervision and pay more attention to behavioral supervision", which was based on the reality of China's financial market of continuously advancing and getting increasingly complex at the same time. With market-oriented reforms deepening and China's relevant financial institutions showing a trend of integration and cross-industry, conducting regulation only on institutions have been unable to meet requirements. Therefore, it is essential to pay attention to behavioral supervision.

(2) Analysis of Regulatory Authorities

The establishment of China's financial regulatory authorities and related regulatory standards has yet to be further improved. Under the current situation, the rapid development of Internet finance has made supervision forms more complex and changeable. 
First, in terms of regional supervision and coordination, geographical restrictions of individual local supervision are relatively large, which increases the difficulty of cooperation and cooperation. However, P2P "thunderstorm" incidents obviously have the characteristics of Internet crime, namely, cross-area. The contradiction between the two has posed great difficulties to China's financial supervision. Besides increasing the cost of supervision, it also increases the difficulty of risk management.

Second is about the standardization of local regulations. The main body of regional supervision in China is local financial offices. Horizontally, finance offices of different places have different authority levels. Vertically, the financial supervision structure is uneven. At the same time, powers and functions of local financial supervision authorities are still scattered, and some regulatory functions will be in the hand of government agencies, which requires that further reform of the regulatory agencies should put emphasis on reforming local regulatory agencies, and promote the centralization of financial supervision authorities as well as structure standardization.

(3) P2P Online Lending Platforms

The Internet has the characteristics of fast speed and wide range in information dissemination. And once P2P online lending platforms go bankrupt, there will appear a series of bad social impacts. To begin with, the Internet accelerates the dissemination of information. When an online lending platform goes bankrupt, it will cause investors to question the credit of the online lending platforms, which in turn leads to the collapse and bankruptcy of other platforms. Second, Internet technology brings more participants of P2P lending, and the expansion of borrowing and lending parties will further cause widespread loss of insolvency and then trigger a chain reaction, leading to bankruptcy and liquidation of more platforms.

Meanwhile, P2P online lending platforms themselves have the unique characteristics of evading supervision. Take audit supervision as an example, China's P2P audit measures are often difficult to achieve strong constraints on those platforms. Moreover, some platforms perform perfunctorily when conducting audit information disclosure, and even, more directly, ignore relevant self-regulatory rules. Sometimes, it is also difficult to ensure the authenticity of the information disclosed by platforms.

(4) Imperfect Infrastructure of the Market Economy

In addition to laws and regulations, a well-developed financial market requires relevant supporting infrastructure such as a sound social credit system, strict industry codes, sophisticated risk prevention and control systems, and even some unwritten social atmosphere, for example, the spirit of contract. Although these factors do not directly promote the improvement of the financial supervision system, they have invisibly facilitated the progress of this system.

Compared with developed capitalist countries such as European countries and the United States, China started late in entering the market economy. Although the state has vigorously promoted "infrastructure construction" in recent years, for example, the 12th Five-Year Plan proposed establishing and improving the social credit system, and the 13th National Congress proposed improving risk prevention and control systems, the rise of the so-called "soft power" such as "business ethics" and "contractual spirit" will still take a long time to form.

\section{Policy Suggestions}

\subsection{Accelerating Unified Legislative Supervision}

Existing laws and regulations pertaining to Internet finance should be integrated, and special laws for all branches of Internet finance should be introduced on the basis of having no conflicts with existing laws. A legal basis should be provided for Internet financial supervision so that the regulation of Internet finance can shift from administrative supervision to legislative supervision.

\subsection{Integrating Central and Local Financial Regulatory Authorities}

First of all, it is necessary to clarify the functions of various financial regulatory agencies when conducting supervision on P2P online lending platforms at the central level. Secondly, in order to deal with cross-regional online lending crimes, it is important to establish a unified information 
database. During the establishment of the filing system, emphasis should be put on the sharing of record data and the enhancement of cooperation between regions so as to improve the ability to combat cross-regional online lending crimes. Thirdly, standardization reforms of local financial regulatory agencies should be carried out. Also, it is essential to unify the regulations concerning organizational structure and authority of local financial institutions.

\subsection{Improving Industry Self-discipline}

It is advisable to mobilize the National Internet Finance Association to promote self-discipline and regulation within the Internet finance industry. Industry associations need to cooperate with government supervision in terms of information disclosure, credit information systems, and market access based on their own positioning. Since industry associations are not government agencies but spontaneous industry organizations, supervision should be centered on prevention.

\subsection{Improving Relevant Infrastructure}

First, the enforceability of third-party auditing system should be enhanced and administrative regulations on auditing need to be transformed into legal provisions quickly. The government should actively cooperate with third-party auditors and guide the long-term disclosure of information of platforms. Second, P2P should be included in the credit system as an important consideration for personal credit reporting. At the same time, the introduction of a private credit information system is worth considering, which can provide more credit reference concerning P2P online lending platforms to a certain extent, thus reducing risks of those platforms.

\section{Conclusion}

This paper applies Smith's "Policy Implementation Process Model" to analyze P2P online lending - a branch of Internet finance. Based on P2P, an industry branch which is hard to regulate and involves high risks, it points out some existing regulatory systems with the aim to provide some ideas for improving the existing regulatory system. However, this paper still has certain deficiencies in some aspects. For instance, it lacks support of mathematical models, while in-depth quantitative analysis is more conducive to understanding the inadequacies of $\mathrm{P} 2 \mathrm{P}$ online lending supervision; also, the dynamic part of the model needs supplement and improvement.

The P2P online lending platform plays a significant role facilitating SME financing, and can diversify public investment. However, at a time when "thunderstorm" incidents frequently occur in the P2P online lending platform, public economic interests and macro financial stability urgently need a sound regulatory system to escort.

\section{References}

[1]. Xie Ping \& Zou Chuanwei \& Liu Haier. The Fundamental Theory of Internet Finance [J]. Journal of Financial Research, 2015 (08):1-12.

[2]. Wu Xiaoqiu. Internet Finance: The Logic of Growth [J]. Finance \& Trade Economics, 2015 (02):5-15.

[3]. Pi Tianlei \& Zhao Tie. Internet Finance: Category, Innovation and Prospects [J]. Finance \& Economics, 2014 (06):22-30.

[4]. Xie Ping \& Zou Chuanwei. Study of Internet Based Finance Mode [J]. Journal of Financial Research, 2012 (12):11-22.

[5]. Yang Dong. The Legal Regulation of Internet Finance-A Perspective Based on Information Tools [J]. Social Sciences in China, 2015 (04):107-126+206.

[6]. He Wenhu. Research on the Risk Regulation of China's Internet Finance [J]. South China Finance, 2014 (10):45-49. 
[7]. Ma Xuesong. The Institutional Logic of Political World: A Study Based on New Institutionalism in Political Science [D]. Jilin University, 2010.

[8]. Li Deguo \& Cai Jingjing. Analysis of the Technique and Methods of Western Policy Evaluation [J]. Science of Science and Management of S. \& T., 2006 (04):65-69.

[9]. James G. March \& Johan P. Olsen \& Yun He. Detailed Explanation of the New Institutionalism [J]. Foreign Theoretical Trends, 2010 (07):41-49.

[10]. Lou Guanhua. Policy Cycle and Policy Termination [J]. Journal of the Socialism Institute of Yunnan, 2007 (04):28-30.

[11]. Zhang Xiaoming. Theoretical Analysis of Public Policy Process: Western Reference and Local Resources [J]. Journal of University of Science and Technology Beijing (Social Sciences Edition), 2013, 29 (04):95-104.

[12]. He Huabing. Review and Outlook of Policy Process Theory-Literature Review [C]. Chinese Public Administration Society, 2007:8.

[13]. Ding Huang. On Lindblom's Theory of Incrementalist Policy-making [J]. Studies in International Technology \& Economy 1999 (03):20-27.

[14]. Zou Shinian. Analysis of the Public Policy Theory Model and China's Public Policy Theory Model Selection [J]. Economic Research Guide, 2009 (16):195-197.

[15]. Han Donglin \& Xu Bo \& Ren Qiaoqiao. Four-dimensional Evaluation of Grassroots Cadres' Implementation of Land Right Confirmation Policy: An Explanation of the Smith's Model [J]. Journal of Anhui Agricultural University (Social Science Edition), 2017, 26 (06):8-12+71.

[16]. A Bangkun \& Ruan Jinyang. Internet Finance: Regulations and Legal Rules [J]. FINANCIAL REGULATION RESEARCH, 2014 (03):57-70.

[17]. He Wenhu \& Yang Yunlong. Research on the Risk Regulation of China's Internet FinanceFrom the Perspective of the Institutional Factors and Non-institutional Factors [J]. JOURNAL OF FINANCIAL DEVELOPMENT RESEARCH, 2014 (08):48-54.

[18]. He Jiaqi \& Tian Jing. Analysis of China's P2P Network Lending Alienation Mode and Legal Regulation [J]. Zhejiang Finance, 2015 (05):4-9.

[19]. Yan Xiaoqin. Legal Regulations of P2P Network Lending [D]. Lanzhou University, 2016.

[20]. Ding Fangda. International Experience of Internet Financial Supervision and Its Enlightenment to the Chinese Government: Taking P2P Network Credit as an Example [J]. Journal of Sichuan Administration College, 2017 (01):9-16.

[21]. Qiu Xun \& Shen Rui. The Problems and Countermeasures of the Legal Regulation of P2P Lending Industry [J]. JOURNAL OF JIANGXI FINANCE COLLEGE, 2017, 30 (02):47-53.

[22]. Deng Dehong. Research on Regulation of P2P Internet Lending [J]. Legal System and Economy, 2016 (10):123-124.

[23]. Liu Xuewen. Research on the Regulation of P2P Lending Platform Operation [D]. Jilin University, 2017. 